$\underset{\text { Bastern }}{\text { EFA }}$

Eastern

Association

The Financial Review 40 (2005) 281-304

The Financial Review

\title{
Nasdaq Trading and Trading Costs: 1993-2002
}

\author{
Bonnie F. Van Ness \\ University of Mississippi \\ Robert A. Van Ness* \\ University of Mississippi \\ Richard S. Warr \\ North Carolina State University
}

\begin{abstract}
Nasdaq spreads decline from 1993 to 2002, largely independently of tick-size reductions. Trade size declines, consistent with greater retail investor activity. Using the method of Chordia, Roll, and Subrahmanyam (2001), we find that concurrent market returns strongly affect liquidity and trading activity. Liquidity exhibits distinct day-of-the-week patterns. There is little evidence that macroeconomic announcements or changes in key interest rates affect Nasdaq stocks overall; but in the bear market, we find a relation between some of these variables and effective spreads, which we interpret as consistent with Nasdaq participants' paying greater attention to fundamentals after the market crash.
\end{abstract}

Keywords: bid-ask spread, liquidity, Nasdaq, order handling rules, tick size, trading costs, trading activity

JEL Classifications: G14, G18

* Corresponding author: University of Mississippi, 233 Holman Hall, University, MS 38677; Phone: 662-915-6940; Fax: 662-915-7968; E-mail: rvanness@bus.olemiss.edu.

We would like to thank Kee Chung, Ken Cyree, Michael Goldstein, Tom McInish, Andriy Shkilko, Robert Wood, Cynthia Campbell and Arnie Cowan (the editors), session participants at the 2004 Financial Management Association annual meeting, and an anonymous referee for helpful comments. Bonnie Van Ness acknowledges support from a Hearin Foundation grant, School of Business Administration, the University of Mississippi. 


\section{Introduction}

The purpose of this study is to provide the first extensive time-series analysis of trading and trading costs for the Nasdaq stock market. Extended time-series studies using stock level transaction data are difficult to undertake due to the significant data requirements; and as a result, there are relatively few of these studies. A notable exception is Chordia, Roll, and Subrahmanyam (2001), who perform one of the longest time-series market microstructure studies. They examine liquidity (spreads, depth, and activity) for all NYSE-listed stocks over an 11-year period (1988-1998), and provide the only other comprehensive long-run study of trading activity that we are aware of. There is no equivalent research on the long-run trading and trading costs on Nasdaq. ${ }^{1}$

Our examination of the long-run trading activities of Nasdaq stocks serves several purposes. First, we provide a partial comparison with Chordia, Roll, and Subrahmanyam (2001) and point out differences between trading patterns on the NYSE and Nasdaq (note that our study period is from 1993 to 2002, whereas Chordia, Roll, and Subrahmanyam's NYSE period is from 1988 to 1998). Second, we study the long-run impact of the order handling rules and other market changes on the trading behavior and liquidity of Nasdaq stocks. While other researchers analyze changes in trading activity and spreads around the order handling rules and minimum tick-size changes, we determine whether the changes in spreads and trading activity occur only around the rule change or over an extended period. ${ }^{2}$ Finally, we look at market behavior in bull and bear markets.

The period 1993-2002 was one of significant change for the Nasdaq market. During this period, we experienced a bull market in which Nasdaq stocks symbolized the technology boom that swept the economy. In 1993, Nasdaq stocks made up about $13 \%$ of the value of the three U.S. stock markets (Nasdaq, AMEX, and NYSE). At the peak of the bull market, Nasdaq stocks constituted $35 \%$ of the total value, but by the end of our sample the proportion had fallen back to $17 \% .^{3}$

The 1990s also were a period of turmoil and intense regulatory activity for the Nasdaq market. Christie and Schultz (1994) and Christie, Harris, and Schultz (1994) brought negative attention to Nasdaq by reporting evidence of implicit collusion among market makers. In the aftermath of these studies, the Securities and Exchange Commission (SEC) instituted the order handling rules which dramatically changed the

\footnotetext{
${ }^{1}$ Schultz (2000) examines 30 Nasdaq stocks from January 1993 to June 1996.

${ }^{2}$ Barclay et al. (1999) examine the effects of the order handling rules on Nasdaq. Goldstein and Kavajecz (2000) examine the change to 1/16ths on the NYSE. Bessembinder (1999) examines both the NYSE and Nasdaq, after the order handling rules and tick size change to 1/16ths. Bessembinder (2003) examines both the NYSE and Nasdaq after the change to decimals.

${ }^{3}$ Nasdaq reached its highest proportion of the total market capitalization in February 2000. These proportions were estimated using all stocks listed on the three exchanges and reported in the CRSP database.
} 
operations of the Nasdaq market. ${ }^{4}$ Nasdaq, like the NYSE, also reduced minimum tick size for trading and quoting from $1 / 8$ ths of a dollar to $1 / 16$ ths to the current decimal tick size. ${ }^{5}$ There is extensive literature examining the impact of these rule changes, but our paper is the first to put them in the context of a long time-series.

Like the work of Chordia, Roll, and Subrahmanyam (2001), this paper is atheoretical in nature (largely because no long-run theories of liquidity and trading patterns exist) and can be described as an exploratory study. However, like Chordia, Roll, and Subrahmanyam (2001), we attempt to answer several questions. First, to what degree is there daily variation in market activity and liquidity in the Nasdaq market? Second, are daily variations in liquidity and trading activity related to specific seasonalities such as days of the week or to macroeconomic announcements? Third, to what extent are liquidity and trading activity related to market return conditions? Fourth, to what extent have retail investors affected the market? And finally, do spread reductions occur largely around the tick-size reductions or is there evidence of a long-run trend?

Our main findings are: spreads decline steadily from 1993 to 2002, and the decline appears unrelated to reductions in minimum tick sizes; trade sizes have become smaller and trading frequency has increased, but the changes do not appear to be caused directly by tick-size reductions; market liquidity and trading activity are strongly related to concurrent market returns, but appear unrelated to previous market returns and volatility; and there are persistent day-of-the-week effects, with Fridays characterized by higher spreads and lower volume and Tuesdays having the lowest spreads and highest volume. We find little overall relation between spreads and macroeconomic events and interest rates; however, during the bear market period, some macroeconomic announcements and interest rate changes affect spreads.

\section{Data}

The data come from the TAQ (NYSE Trade and Quote) database. We use all trades and quotes for Nasdaq-listed stocks with four-digit tickers from 1993 (the inception of the TAQ data) to 2002. We exclude firms with tickers of more than four digits because many are alternate class stock, ADRs, warrants, etc. We exclude any trade or quote that is marked as late, out of order, reported with errors, or in which the bid price is greater than the ask price. We also exclude all trades and quotes that occur prior to 9:30 am or after 4:00 pm. As discussed in the Introduction, long-run time-series studies using transaction data are hampered by the magnitude of the data

\footnotetext{
${ }^{4}$ The rules were phased in for all Nasdaq National Market System (NMS) stocks between January 20 and October 13, 1997.

${ }^{5}$ On June 2, 1997, the minimum tick size on Nasdaq changed from 1/8ths of a dollar to $1 / 16$ ths for stocks with a price greater than $\$ 10$. On March 12, 2001, the Nasdaq Stock Market began its decimal test phase with 14 securities, followed by another 197 stocks on March 26, 2001. All remaining Nasdaq stocks converted to decimal trading on April 9, 2001.
} 
sets; during our sample period, we have more than 2.4 billion trades $(2,451,688,124)$ and more than 2 billion quotes $(2,047,614,805)$.

Our basic approach follows Chordia, Roll, and Subrahmanyam (2001). We replicate their variables as closely as possible and our analysis focuses on the spread, effective spread, trade size, and volume. We estimate the following variables of interest for each stock, then average them on a daily basis (for each stock); the average for all stocks is used as that daily observation.

Quoted spread: The quoted bid-ask spread associated with the transaction.

Percentage quoted spread: The quoted bid-ask spread divided by the midpoint of the quote.

Effective spread: The difference between the execution price and the midpoint of the prevailing bid-ask spread.

Percentage effective spread: The effective spread divided by the midpoint of the prevailing bid-ask quote.

Volume: The total share volume during the day.

Number of trades: The total number of trades during the day.

Dollar volume: The total dollar volume (number of shares multiplied by the transaction price) during the day.

Unlike Chordia, Roll, and Subrahmanyam (2001), we are unable to analyze depth, which the TAQ database does not report accurately for Nasdaq stocks. ${ }^{6}$ We employ several screens to minimize data errors. We drop observations where the quoted spread is greater than $\$ 5$, the effective spread/quoted spread is greater than 4 , the percent effective spread/percent quoted spread is greater than 4 , or the quoted spread/transaction price is greater than 0.4 .

\section{Results}

\subsection{Changes in liquidity and trading activity from 1993 to 2002}

Table 1 provides summary statistics for the main variables. Over the 10 -year period, the average quoted spread and effective spread is $\$ 0.3159$ and $\$ 0.2224$, respectively. Nasdaq daily volume ranges from 53.6 million shares traded to 3.55 billion shares. Figure 1 shows the daily share volume on Nasdaq for the entire period. $^{7}$ The share volume peaks around the end of the bull market (March 2000). The pattern of aggregate share volume mirrors the level of the market quite closely

\footnotetext{
${ }^{6}$ For Nasdaq stocks, TAQ reports the quoted depth of the first market maker at a particular quote. For example, if there are two dealers that have the best ask price, and one dealer is quoting a depth of 500 shares and the other dealer 2,000 shares, the depth reported in the TAQ data will be the dealer with the first quote at that ask price. So, while the total depth is 2,500 shares, the TAQ data will show a depth of either 500 shares or 2,000 shares, depending on which quote was entered first.

${ }^{7}$ Figures 1-4 indicate the order handling rules' implementation period as a pair of vertical dashed lines, and the tick size reductions (first to $1 / 8$ ths and then to decimals) as a pair of solid vertical lines.
} 
Table 1

\begin{tabular}{|c|c|c|c|c|c|}
\hline \multicolumn{6}{|l|}{ Summary statistics } \\
\hline \multicolumn{6}{|c|}{$\begin{array}{l}\text { This table presents summary statistics for Nasdaq stocks from } 1993 \text { to } 2002 \text {. Each variable is estimated by } \\
\text { first averaging the variable for each stock every day and then taking the average of these averages for each } \\
\text { day in the sample. The summary statistics presented here are based on the daily averages for the entire } \\
\text { period. There are } 2,520 \text { days in the sample (the number of daily observations). The variables are defined as } \\
\text { follows. Quoted spread: the quoted bid-ask spread associated with the transaction. Percent quoted spread: } \\
\text { the quoted bid-ask spread divided by the midpoint of the quote (in percent). Effective spread: the effective } \\
\text { spread, i.e., the difference between the execution price and the midpoint of the prevailing bid-ask spread. } \\
\text { Percent effective spread: the effective spread divided by the midpoint of the prevailing bid-ask quote (in } \\
\text { percent). Volume: the total share volume during the day. Number of trades: the total number of trades } \\
\text { during the day. Dollar volume: the total dollar volume (number of shares multiplied by the transaction } \\
\text { price) during the day. }\end{array}$} \\
\hline Variable & Mean & Median & $\mathrm{SD}$ & Mini & Maxi \\
\hline 0 & 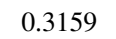 & & 0 & & \\
\hline$\%$ Quoted spread & 0.0431 & 0.0433 & 0.0100 & 183 & 104 \\
\hline Effective spread & 0.2224 & 0.2419 & 0.0653 & 0.0897 & 0.8010 \\
\hline$\%$ Effective spre & 0.0298 & 0.0301 & 0.0060 & 0.0176 & 0.0686 \\
\hline Total daily share volume (millions) & 923 & 662 & 691 & 53.6 & 3,550 \\
\hline Total daily dollar volume (millions) & 10,100 & 762 & 820 & 55.3 & 46,400 \\
\hline Total daily trades & & & & 36,012 & $4,001,706$ \\
\hline
\end{tabular}

(share volume is the total number of shares traded, not the dollar volume), suggesting the likelihood of a link between market returns and the intensity of trading activity. We examine this link in section 3.3.

Previous studies report trading cost reductions around the order handling rules and tick-size changes (see Footnote 2). Using our 10-year sample, we can determine whether spreads are narrowing only at these events or over an extended period. To test, we divide the period into six-month intervals and test the changes in liquidity between the intervals. The results appear in Panel A of Table 2; and Figures 2 and 3 present the daily time-series of selected Panel A variables. Spreads decline steadily over the entire period. ${ }^{8}$ Average quoted spreads are $\$ 0.4465$ at the beginning of 1993 and decline in almost all subsequent six-month periods until average quoted spreads are $\$ 0.1625$ during the last six months of 2002 . This decline does not appear to be merely a result of rule changes and minimum tick-size reductions. ${ }^{9}$ In 12 of the 19 periods, quoted spreads decline. Spreads widen in only four periods (the remaining three are not significant). Further, while the periods of the tick-size reductions (indicated by the superscripts "c" and "d") correspond to some of the largest reductions in spreads;

\footnotetext{
${ }^{8}$ Schultz (2000), analyzing a sample of 30 Nasdaq stocks from January 1993 to June 1996, also finds that spreads are steadily declining during this period.

${ }^{9}$ This extends the findings of Huang and Stoll (1996), who report Nasdaq spreads increasing for much of the 1980s and declining in the early 1990s, despite the absence of rule changes that could explain the decline.
} 


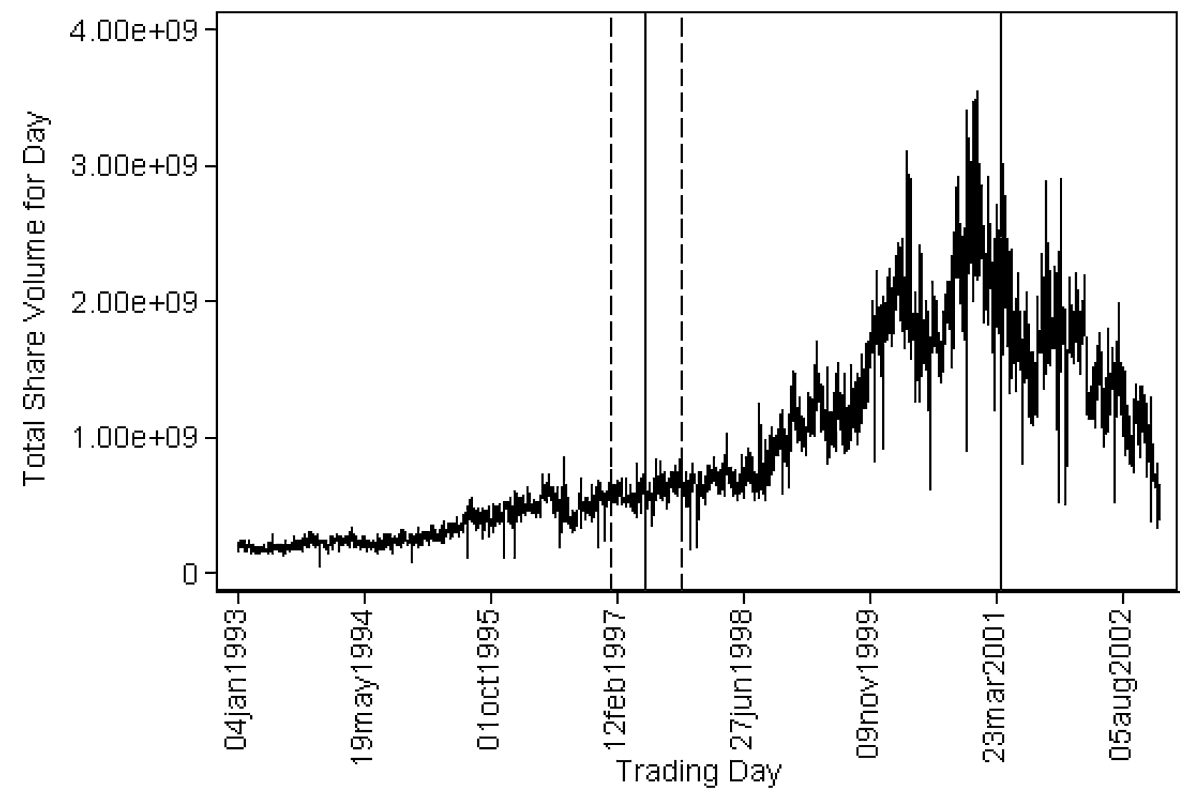

Figure 1

Nasdaq total share volume from 1993 to 2002

they account for about $36 \%$ of the total reduction in spreads that occur from 1993 to 2002. ${ }^{10}$ Although tick reductions are correlated with reduced spreads, our evidence suggests that the tick-size reductions come into effect at a time when spreads are already declining.

The changes in the other spread measures in Table 2 display a similar pattern with an overall steady decline. The percentage spread measures show a significant increase around the end of the bull market (after March 2000). This increase in percentage spreads is consistent with falling prices and with spreads' exhibiting some stickiness as prices fall.

In Panel B of Table 2, we report the average trade statistics and their changes over the period. The average trade size shows a declining trend, whereas the number of trades shows a steady increase until the end of the bull market. These series are presented in Figure 4. Previous research reports that the SEC order handling rules and the tick-size changes result in smaller trades (or, trades broken into multiple smaller trades). Consequently, we expect the average trade size to be smaller after

\footnotetext{
${ }^{10}$ We estimate the spread reduction due to the tick-size change as the difference in spreads six months before and six months after the change. The sum of the two differences (for both the tick reduction events) is divided by the total spread reduction over the sample.
} 


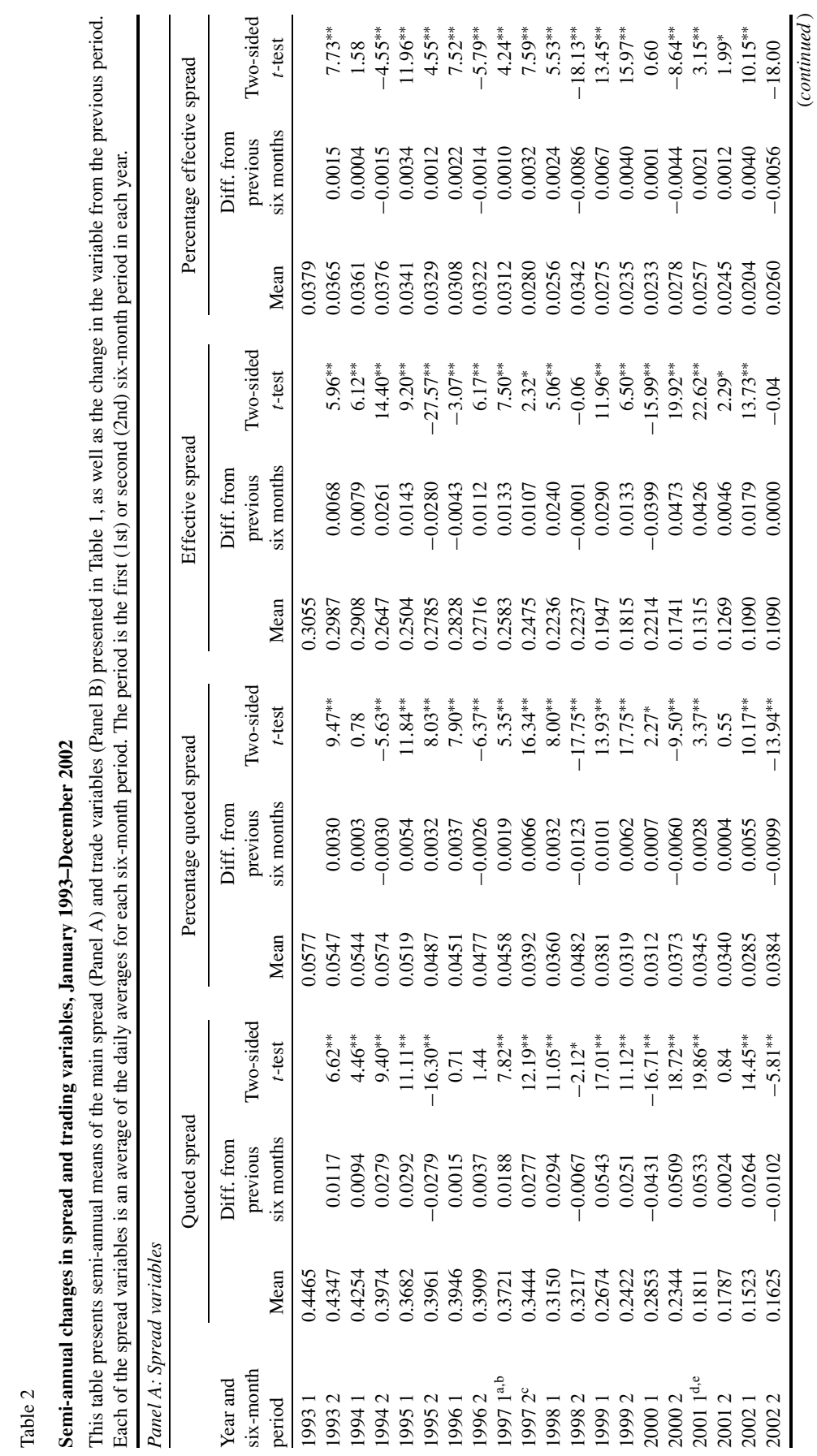




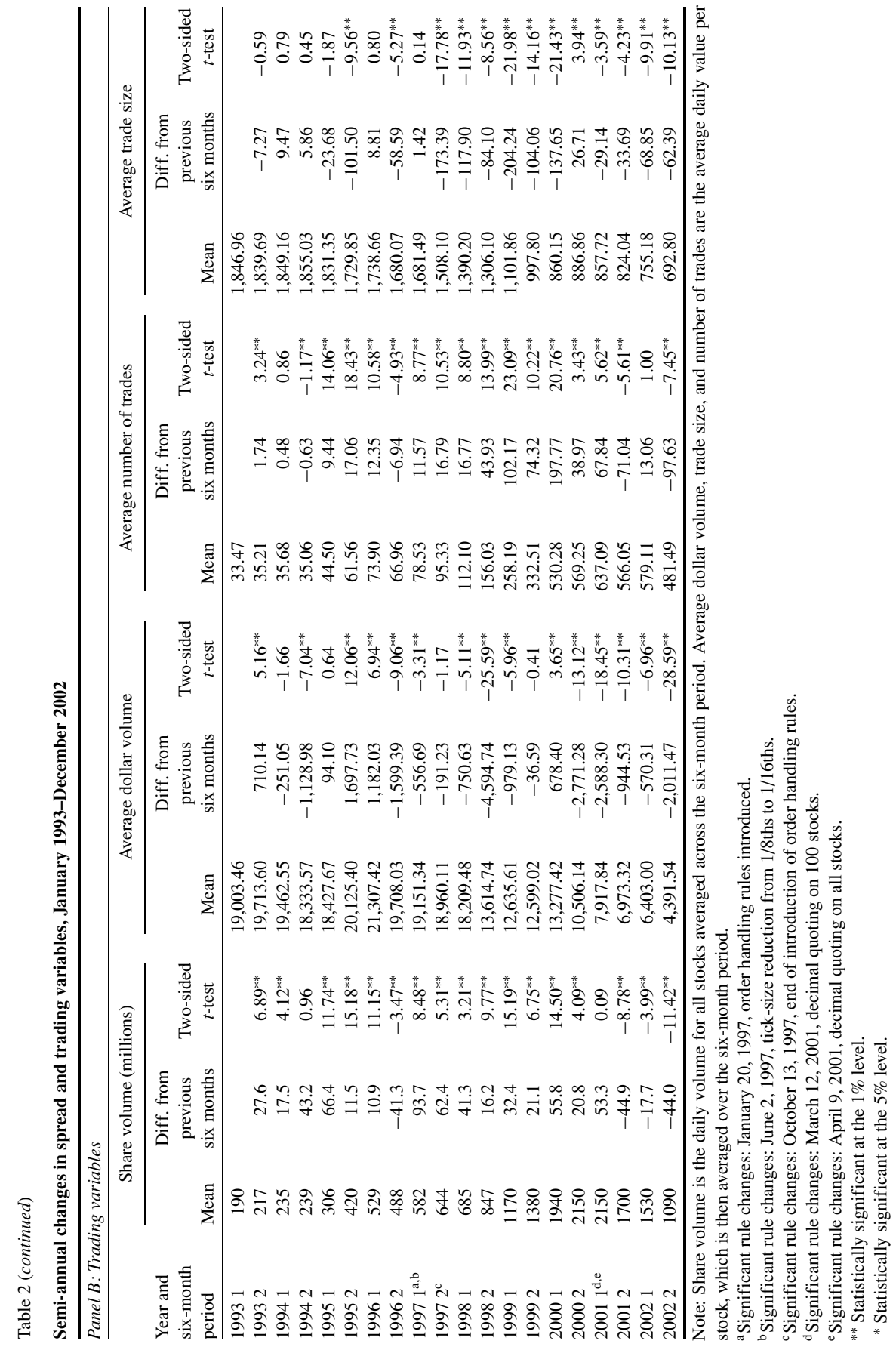




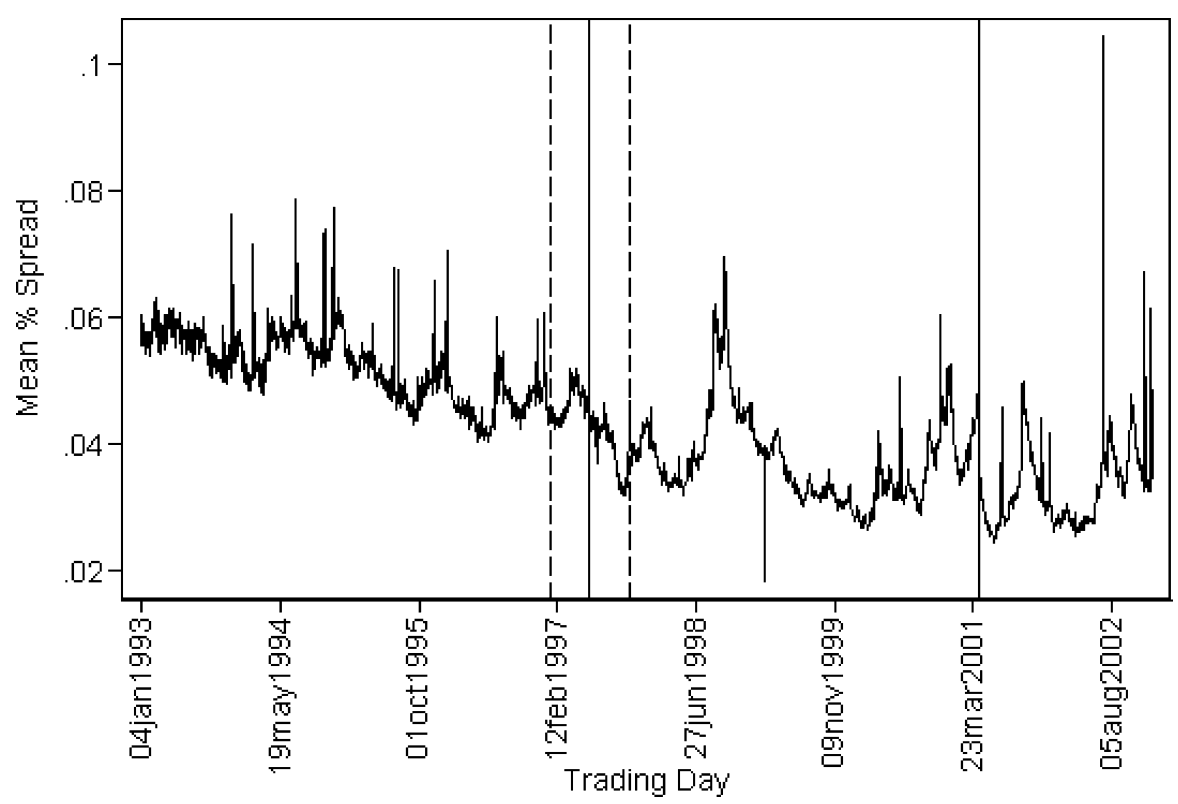

Figure 2

Nasdaq percentage quoted spreads from 1993 to 2002

the rule and tick-size changes, but it seems to decline in years with no rule changes (1993-1994 is the only year with an increase in the average trade size). An alternative explanation for the general downward trend in trade size is that the increased direct market participation by retail investors results in lower average trade sizes. This explanation is also supported by the close relation that appears between total volume and market price level — a relation that would exist if retail investors exhibit herding and attempt to chase returns when they trade.

\subsection{Correlations and autocorrelations}

Table 3 presents the correlations of the percentage changes in our variables. Similar to Chordia, Roll, and Subrahmanyam (2001), volume (both in shares and dollars) and spreads (quoted and percentage quoted) are negatively related to one another. As expected, we find a negative relation between effective spreads and volume, although Chordia, Roll, and Subrahmanyam find that effective spreads and volume are positively related for NYSE stocks, which they say is unexpected.

Table 4 presents the autocorrelations of quoting and trading activity variables for five trading days. While our autocorrelations are similar to those of Chordia, Roll, and Subrahmanyam (2001), the Nasdaq market appears to have autocorrelations with longer lags. For example, Chordia, Roll, and Subrahmanyam report significant 


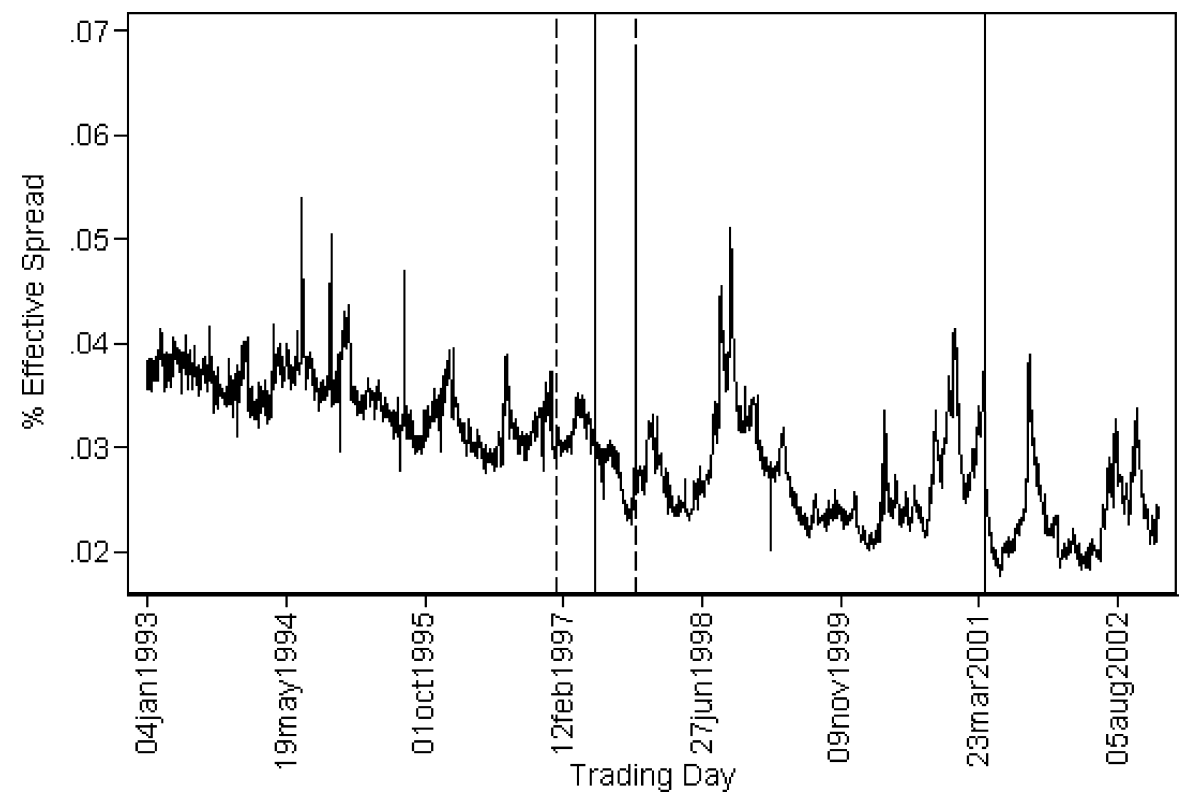

Figure 3

Nasdaq percentage effective spreads from 1993 to 2002

autocorrelations with lags of two days for changes in quoted spreads, whereas we find that Nasdaq autocorrelations exhibit lags of four days. Similarly, the autocorrelation of Nasdaq trading activity variables also exhibits longer lags (four days) than those of NYSE (two days) in Chordia, Roll, and Subrahmanyam. Negative autocorrelations are consistent with mean reversion of the various trading metrics. However, Chordia, Roll, and Subrahmanyam suggest that, in the case of the spreads, negative autocorrelation may also result from discreteness in tick size, even though their data set incorporated only about 18 months after the change to $1 / 16$ ths. Our data set spans two tick reductions and allows us to test whether the magnitude of the autocorrelations declines following tick-size reductions. The results of these tests are presented in Panel B of Table 4. During the first period, when the minimum tick size is $1 / 8$ th, we see persistent negative autocorrelation that spans four lags. However, after the tick-size reductions, only the first and second lags are significant, consistent with price discreteness accentuating the lags.

\subsection{Determinants of liquidity and trading activity}

In this section, we look at factors that might determine daily changes in market liquidity and trading activity. Our method follows that of Chordia, Roll, and 


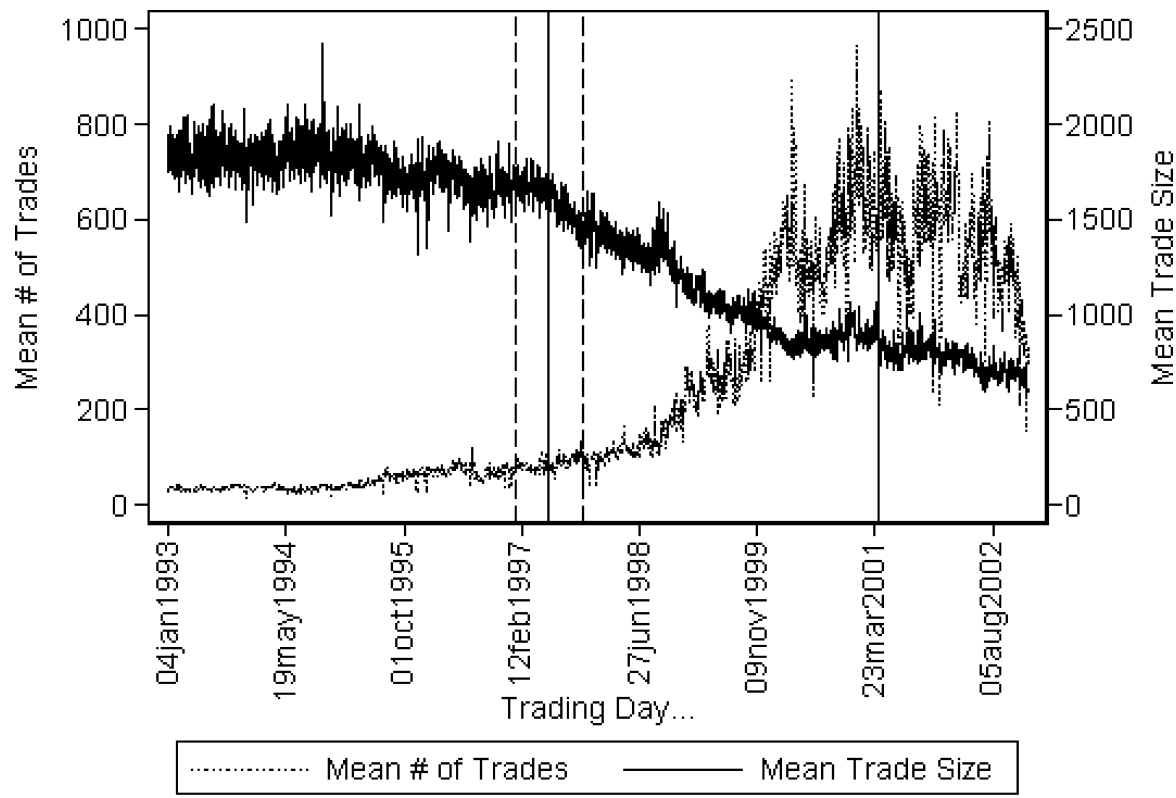

Figure 4

Nasdaq daily average trade size and daily number of trades per stock from 1993 to 2002

Subrahmanyam (2001). The basic approach is to regress daily changes in the marketwide microstructure variables on measures of market activity, calendar time, macroeconomic events, and levels of key market interest rates. Recent studies report a significant relation between market maker competition and Nasdaq liquidity. ${ }^{11} \mathrm{We}$ include the daily change in the number of market makers as a potential determinant of changes in the microstructure variables.

$$
\begin{aligned}
& {\left[\text { Dependent }_{i t}\right]=b_{0}+b_{1} M K T+{ }_{i t}+b_{2} M K T-{ }_{i t}+b_{3} M A 5 M K T+{ }_{i t}} \\
& +b_{4} M A 5 M K T-{ }_{i t}+b_{5} M A 5\left|M K T_{i t}\right| \\
& +b_{6-9} \text { Day-of-the-week Dummies }_{t}+b_{10} \text { Holiday }_{t}+b_{11} \text { Short Rate }_{t} \\
& +b_{14} \text { Short Rate }_{t}+b_{15} \text { Term Spread }_{t}+b_{16} \text { Quality Spread }_{t} \\
& +b_{17} G D P(1-2)_{t}+b_{18} G D P(0)_{t}+b_{19} U N P(1-2)_{t} \\
& +b_{20} \operatorname{UNP}(0)_{t}+b_{21} C P I(1-2)_{t}+b_{22} C P I(0)_{t}+\Delta M M \varepsilon_{i t}
\end{aligned}
$$

\footnotetext{
${ }^{11}$ For example, Chung, Chuwonganant, and McCormick (2004) report that market maker competition reduces spreads, and Van Ness, Van Ness, and Warr (2004) find that more market makers reduce adverse selection costs for Nasdaq stocks.
} 
Table 3

Correlations of simultaneous percentage changes

These are the correlations for absolute values of daily percentage changes.

\begin{tabular}{lccccc}
\hline & $\begin{array}{c}\Delta \text { Quoted } \\
\text { spread }\end{array}$ & $\begin{array}{c}\Delta \% \text { Quoted } \\
\text { spread }\end{array}$ & $\begin{array}{c}\Delta \text { Effective } \\
\text { spread }\end{array}$ & $\begin{array}{c}\Delta \% \text { Effective } \\
\text { spread }\end{array}$ & $\begin{array}{c}\Delta \text { Share } \\
\text { volume }\end{array}$ \\
\hline$\Delta \%$ Quoted spread & $0.8442^{* *}$ & & & & \\
$\Delta$ Effective spread & $0.3790^{* *}$ & $0.1824^{* *}$ & & & \\
$\Delta \%$ Effective spread & $0.2931^{* *}$ & $0.3329^{* *}$ & $0.7279^{* *}$ & & \\
$\Delta$ Share volume & $-0.3789^{* *}$ & $-0.3391^{* *}$ & $-0.0796^{* *}$ & 0.0231 & \\
$\Delta$ Dollar volume & $-0.3041^{* *}$ & $-0.2501^{* *}$ & $-0.2231^{* *}$ & $-0.1938^{* *}$ & $0.4994^{* *}$ \\
\hline
\end{tabular}

Note: All variables in this table are measured as daily percentage changes-signified with the prefix $\Delta$.

** Indicates significance at the $1 \%$ level.

${ }^{*}$ Indicates significance at the $5 \%$ level.

Table 4

\section{Autocorrelations of liquidity and trading activity variables}

This table presents the autocorrelation coefficients in the daily percentage changes in the variables presented in Table 1 after omitting the changes at the turn of the year in question. Panel A presents results for the entire sample. Panel B presents results for the change in percentage quoted spreads for selected sub-periods. During the first sub-period the minimum tick size was $1 / 8$ th, during the second sub period the minimum tick size was $1 / 16$ th, and during the final sub period the minimum tick size is $1 / 100$ th.

\begin{tabular}{|c|c|c|c|c|c|}
\hline & \multicolumn{5}{|c|}{ Order (lag in daily observations) } \\
\hline & 1 & 2 & 3 & 4 & 5 \\
\hline \multicolumn{6}{|l|}{ Panel A: full period } \\
\hline \multicolumn{6}{|c|}{ Liquidity variables } \\
\hline$\Delta$ Quoted spread & $-0.4877^{*}$ & $-0.3372^{*}$ & $-0.1865^{*}$ & $-0.1081^{*}$ & -0.0343 \\
\hline$\Delta \%$ Quoted spread & $-0.4211^{*}$ & $-0.2107^{*}$ & $-0.0764^{*}$ & -0.0436 & -0.0131 \\
\hline$\Delta$ Effective spread & $-0.3420^{*}$ & $-0.1991^{*}$ & $-0.0811^{*}$ & -0.0630 & 0.00125 \\
\hline$\Delta \%$ Effective spread & $-0.3114^{*}$ & $-0.1629^{*}$ & -0.0565 & -0.0367 & 0.01678 \\
\hline \multicolumn{6}{|c|}{ Trading activity variables } \\
\hline$\Delta$ Share volume & $-0.3179^{*}$ & $-0.2512^{*}$ & $-0.2021^{*}$ & $-0.0847^{*}$ & 0.0553 \\
\hline$\Delta$ Dollar volume & $-0.6312^{*}$ & $-0.5577^{*}$ & $-0.4616^{*}$ & $-0.2900^{*}$ & 0.0179 \\
\hline \multicolumn{6}{|c|}{ Panel B: Sub periods for $\Delta \%$ quoted spread } \\
\hline 1/8ths $01 / 1993-06 / 1997$ & $-0.5869^{*}$ & $-0.4269^{*}$ & $-0.2676^{*}$ & $-0.1990^{*}$ & -0.0727 \\
\hline $1 / 16$ ths $06 / 1997-03 / 2001$ & $-0.3484^{*}$ & $-0.1442^{*}$ & -0.0445 & -0.0178 & -0.0015 \\
\hline 1/100ths $03 / 2001-12 / 2002$ & $-0.4026^{*}$ & $-0.1752^{*}$ & -0.0434 & -0.0161 & -0.0190 \\
\hline
\end{tabular}

Note: All variables in this table are measured as daily percentage changes-signified with the prefix $\Delta$.

*Indicates a $p$-value of less than 0.0001 for an asymptotic test that the autocorrelation coefficient is zero.

where Dependent $_{i t}$ is either the daily change in the percentage spread, percentage effective spread, dollar volume, or share volume. The independent variables are those used by Chordia, Roll, and Subrahmanyam (2001) and are MKT+ (MKT-): the CRSP equally weighted return if it is positive (negative) and 0 otherwise; MA5MKT+ 
(MA5MKT-): the CRSP equally weighted return over the past five trading days if it is positive (negative) and 0 otherwise; MA5 $|\mathrm{MKT}|$ : the average CRSP equally weighted daily absolute return over the previous five days (all the return variables are expressed as percentages); Monday to Thursday: four dummy variables that take the value 1 if the trading day is a Monday, Tuesday, Wednesday, or Thursday, and 0 otherwise; Holiday: a variable that takes on a value of 1 if a trading day satisfies the following conditions: (1) if Independence Day, Veteran's Day, Christmas, or New Year's Day falls on a Friday, then the preceding Thursday, (2) if any holiday falls on a weekend or on a Monday, then the following Tuesday, (3) if any holiday falls on another weekday, then the preceding and following days (this is always the case for Thanksgiving), and 0 otherwise; Short Rate: the first difference in the Federal Funds rate; Term Spread: the daily change in the difference between the yield on a constant maturity 10-year Treasury Bond and Short Rate; Quality Spread: the daily change in the difference between the yield on Moody's Baa or better corporate bond yield index and the yield on a 10-year constant maturity Treasury bond; GDP(0): 1 on the day of a GDP announcement and 0 otherwise; GDP(1-2): 1 on the two trading days prior to a GDP announcement, and 0 otherwise; $\mathrm{UNP}(0)$, UNP(1-2), CPI(0), CPI(1-2): dummy variables for unemployment and CPI announcements, respectively, paralleling the GDP variables; and $\triangle \mathrm{MM}$ : the daily change in the average number of market makers per stock as reported by CRSP. Our regression specification is likely to suffer from severe autocorrelation (as shown in Table 4). Therefore, we apply the Cochrane-Orcutt iterative correction procedure for first-order autocorrelation.

We briefly outline the rationale for the variables; Chordia, Roll, and Subrahmanyam (2001) provide a comprehensive discussion. The market-return variables (MKT+, MKT-, etc.) are included to capture the impact of concurrent and recent market movements on market liquidity. For example, sudden price changes may cause difficulty for market makers in adjusting inventory levels, resulting in changes in liquidity. The multiple market maker structure of Nasdaq may serve to mitigate this effect. ${ }^{12}$ Recent market movements may also be related to current trading levels if investors employ technical trading strategies or contrarian strategies. In the case of Nasdaq, we suspect that herding, or return chasing behavior by retail investors, may increase the magnitude of the link between past returns and trading activity.

Interest rates are included as possible explanatory variables because of the potential link between margin requirements and short sale costs, which can affect trading activity. In addition, higher interest rates may lead to disintermediation, where investors tilt their portfolios toward interest-paying securities. We include day-ofthe-week dummies as well as holiday dummies to capture any potential behavioral aspects to trading that might surround these dates. Macroeconomic announcements are included because the days when these announcements occur are, arguably, days of

\footnotetext{
${ }^{12}$ For example, see Huang and Stoll (1996) for a discussion on the advantages of the dealer system over the specialist system.
} 
greater market uncertainty and, therefore, may have wider spreads and greater trading activity.

To analyze the determinants of liquidity, we examine: (1) the full period, January 1993-2002, (2) the bull market, December 1993-March 2000, and (3) the bear market, March 2000-December 2002. We also repeat the tests using the Nasdaq composite index instead of the CRSP equal-weighted index for the full sample. Our rationale is that Nasdaq investors may pay more attention to activity within that market rather than to the market as a whole. The Nasdaq composite index is a value-weighted index comprising all Nasdaq stocks.

The results are in Table 5. Examining the market return variables first, we find a negative relation between both quoted and effective spreads and MKT + and MKT(although not significantly so for percentage spread and MKT+). Thus, spreads decline in up markets and increase in down markets (recall that the value of MKT is negative or 0 by construction). The significant impact of down markets suggests that market makers are less willing to trade in poor markets and perhaps more likely to step back from the market. We see a symmetric response for share volume in different markets. Here, volume increases in both up- and down-market conditions, indicating that any uncertainty in the market is greeted with increased trading. For dollar volume, down markets lead to a decline in volume; however, given the result for share volume, the decrease is likely due to the decline in prices that occurs in down markets.

We find no relation between the market trend variables and any of our microstructure variables. Further, MA5 $|\mathrm{MKT}|$, the measure of recent market volatility, is also unrelated to any of the variables - a somewhat surprising result given previous evidence that spreads tend to be correlated with volatility.

We generally find negative relations between the day-of-the-week dummies (Tuesday to Thursday) and spreads, and positive relations with trading activity. The results imply that the constant in our regressions should have a positive sign for spreads and negative sign for volume, because the constant is, in part, picking up the effect of Friday. Although we find a significant relation for volume, the relation is not significant for spreads, providing partial evidence that liquidity and trading decline at the end of the week, and that Tuesday is the most liquid day. The period around holidays is one of decreased liquidity and trading. We find no relation between the spread variables and any of the interest rate or macroeconomic announcement variables. Our results contradict those of Chordia, Roll, and Subrahmanyam (2001), who find that spreads tend to increase with the short-term interest rate and the term Spread. There is a negative relation between changes in the Term Spread, short-term interest rate, and volume, and a positive relation between Quality Spread and volume. The Term Spread relation is consistent with investors moving from stocks to bonds when long-term bond yields increase. Increasing Quality Spreads may occur in periods of economic uncertainty and these results suggest that such times are characterized by greater trading.

Finally, the change in market makers, $\Delta \mathrm{MM}$, is negatively related to percentage spread and positively related to volume. Increases in market makers are associated 


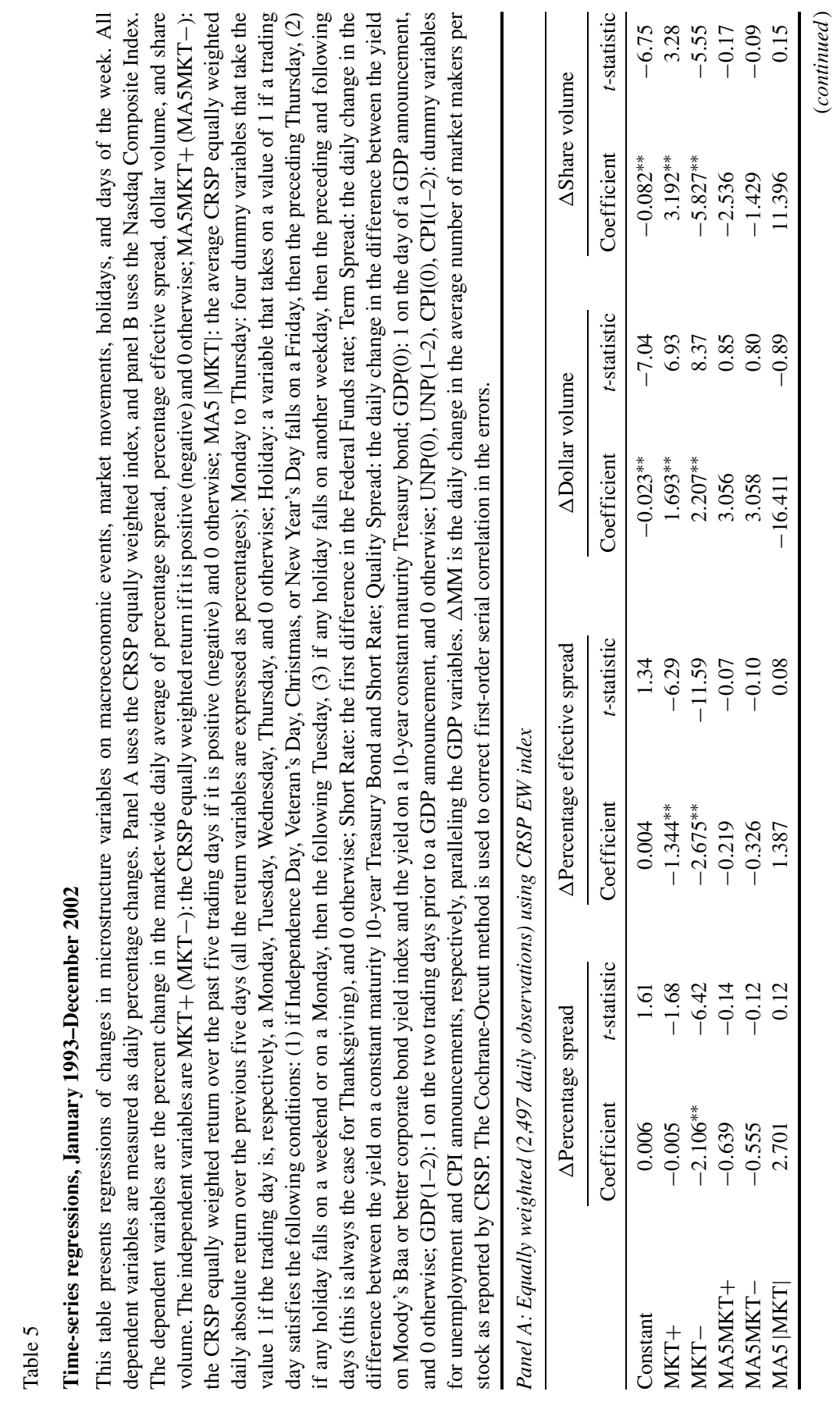




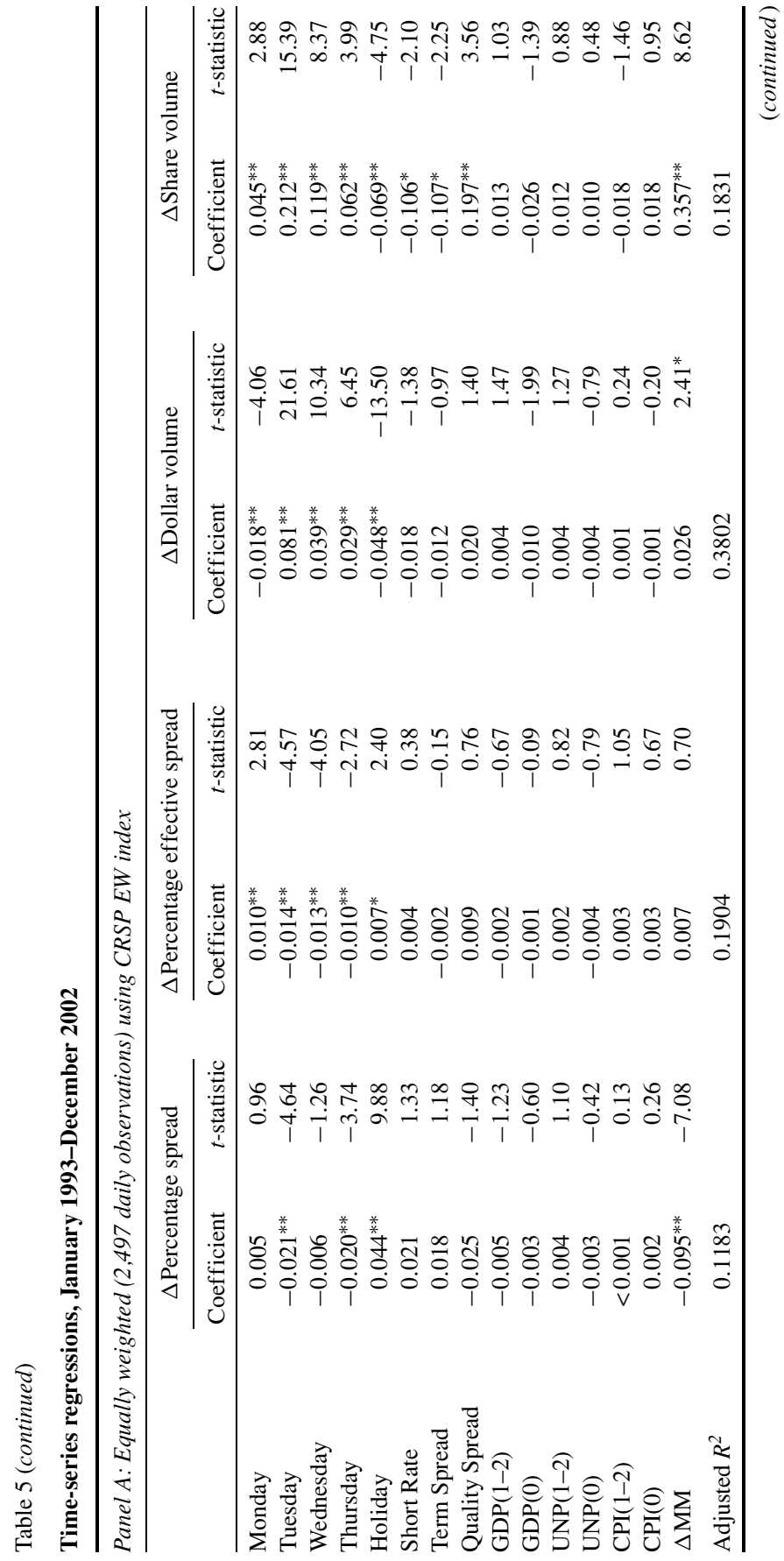




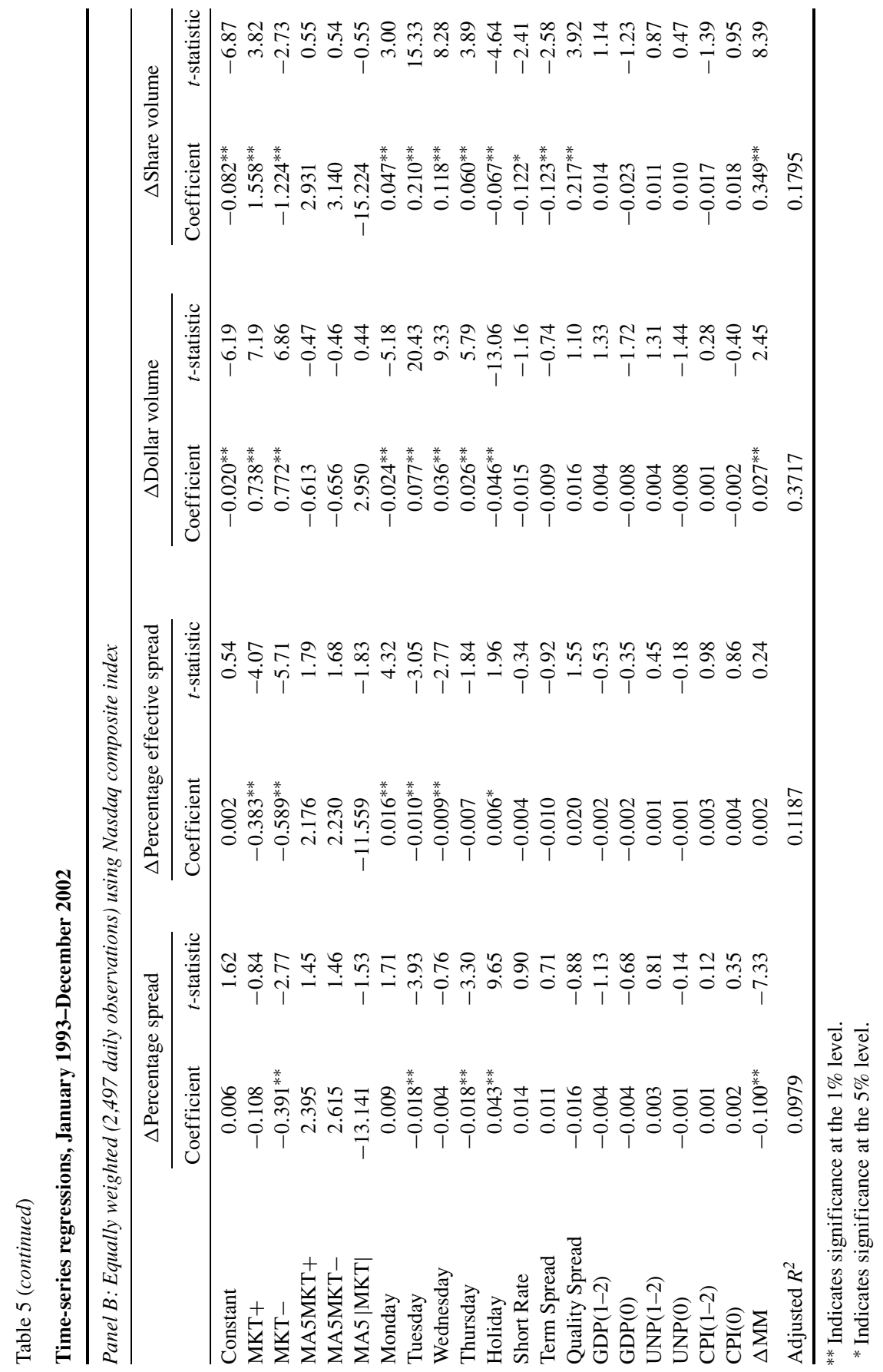


with reduced spreads (presumably through competition) and increased volume, although we recognize that the change in market makers may be endogenous to the current market condition.

We conduct several alternative analyses to attempt to better understand the causes of some of the relations in Panel A of Table 5. First, in Panel B, we replace the CRSP equal-weighted index (used in the MKT variables) with the Nasdaq composite index, which is a value-weighted index of all Nasdaq stocks. Our rationale is that the liquidity of the Nasdaq market may be more closely related to the performance of Nasdaq stocks rather than the market-wide return. Panel B shows little substantial difference in the results from Panel A, except that the MKT coefficients are smaller in magnitude. In fact, the adjusted $R^{2}$ of the Panel B regressions are lower than those of Panel A, indicating that the CRSP index is a better choice for the model.

To the extent that our results differ from those of Chordia, Roll, and Subrahmanyam (2001), we cannot be sure whether the differences are due to differences in the NYSE compared to Nasdaq or due to the periods studied (Chordia, Roll, and Subrahmanyam examine 1988-1998). ${ }^{13}$ We replicate part of our tests for NYSE stocks and present the results in Table 6 . We find no relation between any of the macroeconomic variables and interest rate variables and market quality or activity. Thus, we conclude that the absence of the relation for Nasdaq stocks may be due to the different period studied. The rest of the results for our NYSE sample are broadly similar to those for the Nasdaq sample.

\subsection{Analysis of bull and bear markets}

Our analysis spans both the largest bull market in recent history and one of the most dramatic market declines. Both events, while occurring market-wide, were more concentrated on Nasdaq, as is evident by the significant increase and then decrease of Nasdaq stocks as a proportion of the total market value. Table 7 presents the results using the bull market period from January 1993 to March 10, 2000 (Panel A) and the bear market period from March 11, 2000 to December 31, 2002 (Panel B). We use the CRSP equal-weighted index in Table 7, given the higher $R^{2}$ obtained in Table 5. In Panel A of Table 7, we find generally similar results to those in Table 5, notably that interest rate variables and macroeconomic variables do not seem to affect liquidity. The decrease in volume associated with an increase in the Term Spread and short-term rate is also present in the bull market period.

The bear market regressions presented in Panel B of Table 7 exhibit some differences from the results above. First, the interest rate variables are all significant in the percentage effective spread regression. Short Rate and Term Spread are both negative,

\footnotetext{
13 There are substantial differences between the NYSE and Nasdaq. For example, Atkins and Dyl (1997) show that Nasdaq counts trades differently than the NYSE, while Christie and Huang (1994) and Huang and Stoll (1996) show differences in trading costs and market structure between the NYSE and Nasdaq, and Heidle and Huang (2002) show that there are differences in informed trading between the two exchanges.
} 
Table 6

\section{Time-series regressions for NYSE stocks, January 1993-December 2002}

This table presents regressions of changes in microstructure variables on macroeconomic events, market movements, holidays, and days of the week. All dependent variables are measured as daily percentage changes. The dependent variables are the percent change in the market-wide daily average of percentage spread, percentage effective spread, and share volume. The independent variables are MKT+ $(\mathrm{MKT}-)$ : the CRSP equally weighted return if it is positive (negative) and 0 otherwise; MA5MKT+ (MA5MKT-): the CRSP equally weighted return over the past five trading days if it is positive (negative) and 0 otherwise; MA5 |MKT|: the average CRSP equally weighted daily absolute return over the previous five days (all the return variables are expressed as percentages); Monday to Thursday: four dummy variables that take the value 1 if the trading day is, respectively, a Monday, Tuesday, Wednesday, Thursday, and 0 otherwise; Holiday: a variable that takes on a value of 1 if a trading day satisfies the following conditions: (1) if Independence Day, Veteran's Day, Christmas, or New Year's Day falls on a Friday, then the preceding Thursday, (2) if any holiday falls on a weekend or on a Monday, then the following Tuesday, (3) if any holiday falls on another weekday, then the preceding and following days (this is always the case for Thanksgiving), and 0 otherwise; Short Rate: the first difference in the Federal Funds rate; Term Spread: the daily change in the difference between the yield on a constant maturity 10-year Treasury Bond and Short Rate; Quality Spread: the daily change in the difference between the yield on Moody's Baa or better corporate bond yield index and the yield on a 10-year constant maturity Treasury bond; GDP(0): 1 on the day of a GDP announcement, and 0 otherwise; GDP(1-2): 1 on the two trading days prior to a GDP announcement, and 0 otherwise; UNP(0), UNP(1-2), $\mathrm{CPI}(0), \mathrm{CPI}(1-2)$ : dummy variables for unemployment and CPI announcements, respectively, paralleling the GDP variables. $\triangle \mathrm{MM}$ is the daily change in the average number of market makers per stock as reported by CRSP. The Cochrane-Orcutt method is used to correct first-order serial correlation in the errors.

NYSE stocks. Equally weighted (2,497 daily observations) using CRSP EW index

\begin{tabular}{|c|c|c|c|c|c|c|}
\hline & \multicolumn{2}{|c|}{$\Delta$ Percentage spread } & \multicolumn{2}{|c|}{$\Delta$ Percentage effective spread } & \multicolumn{2}{|c|}{$\Delta$ Share volume } \\
\hline & Coefficient & $t$-statistic & Coefficient & $t$-statistic & Coefficient & $t$-statistic \\
\hline Constant & $0.006^{* *}$ & 4.79 & 0.001 & 0.58 & $-0.045^{* *}$ & -4.79 \\
\hline MKT+ & $-0.749^{* *}$ & -7.21 & $-0.361^{* *}$ & -2.68 & -0.057 & -0.08 \\
\hline MKT- & $-1.403^{* *}$ & -12.39 & $-1.898^{* *}$ & -12.94 & $-5.318^{* *}$ & -6.55 \\
\hline MA5MKT+ & 2.325 & 1.43 & 1.721 & 0.84 & 2.316 & 0.20 \\
\hline MA5MKT- & 2.389 & 1.39 & 1.927 & 0.89 & 3.722 & 0.31 \\
\hline MA5 |MKT| & -11.920 & -1.43 & -9.046 & -0.86 & -11.598 & -0.20 \\
\hline Monday & $-0.008^{* *}$ & -4.89 & 0.001 & 0.22 & $0.057^{* *}$ & 4.46 \\
\hline Tuesday & $-0.018^{* *}$ & -12.45 & $-0.012^{* *}$ & -6.29 & $0.118^{* *}$ & 10.80 \\
\hline Wednesday & $-0.003^{*}$ & -2.54 & -0.000 & -0.19 & $0.053^{* *}$ & 4.76 \\
\hline Thursday & $-0.005^{* *}$ & -3.42 & -0.002 & -0.78 & $0.051^{* *}$ & 4.07 \\
\hline Holiday & $0.009^{* *}$ & 6.29 & $0.005^{*}$ & 2.33 & $-0.026^{*}$ & -2.42 \\
\hline Short Rate & 0.002 & 0.51 & -0.004 & -0.58 & -0.000 & -0.00 \\
\hline Term Spread & 0.002 & 0.45 & -0.005 & -0.77 & -0.039 & -1.06 \\
\hline Quality Spread & -0.001 & -0.19 & 0.008 & 1.09 & 0.016 & 0.38 \\
\hline $\operatorname{GDP}(1-2)$ & -0.001 & -0.96 & -0.001 & -0.73 & 0.005 & 0.56 \\
\hline GDP(0) & -0.000 & -0.18 & 0.001 & 0.60 & -0.009 & -0.62 \\
\hline UNP(1-2) & -0.002 & -1.49 & -0.003 & -1.89 & -0.002 & -0.23 \\
\hline $\mathrm{UNP}(0)$ & 0.000 & 0.04 & 0.0027 & 0.57 & 0.018 & 1.18 \\
\hline CPI(1-2) & 0.001 & 1.12 & 0.001 & 0.74 & -0.009 & -0.99 \\
\hline $\mathrm{CPI}(0)$ & -0.002 & -1.20 & -0.001 & -0.29 & 0.005 & 0.40 \\
\hline Adjusted $R^{2}$ & 0.2378 & & 0.1576 & & 0.0796 & \\
\hline
\end{tabular}

** Indicates significance at the $1 \%$ level.

* Indicates significance at the 5\% level. 


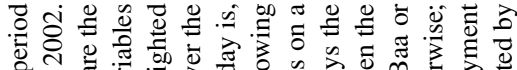

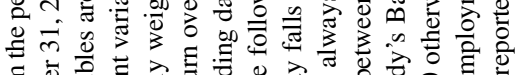

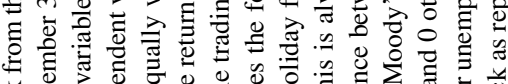

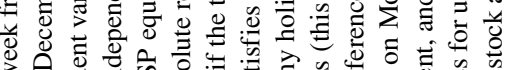

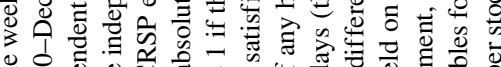

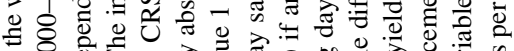

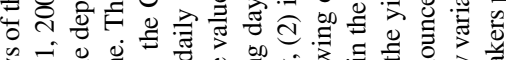

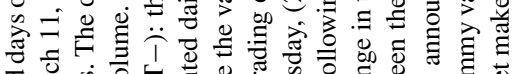

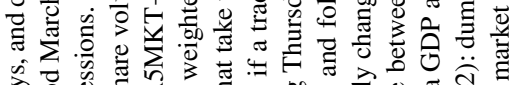
خे

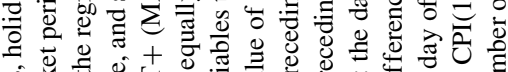

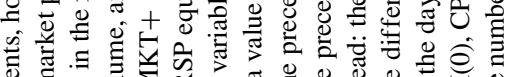

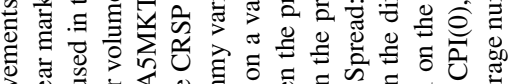

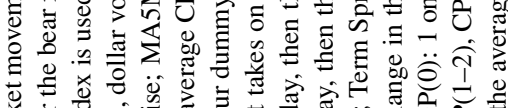

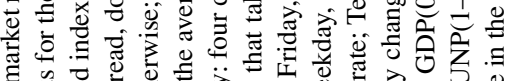

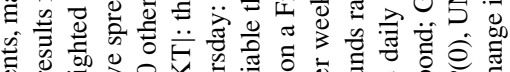

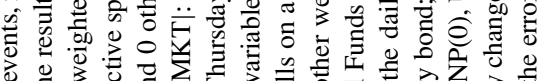

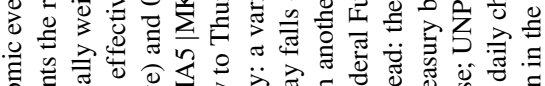

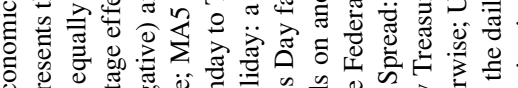

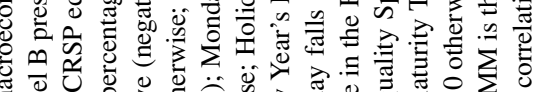

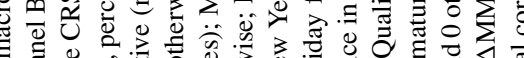

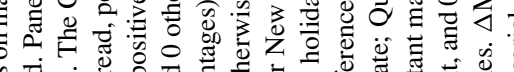

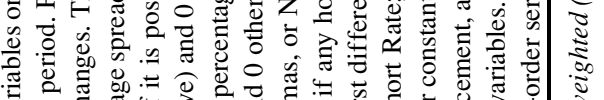

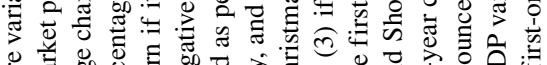

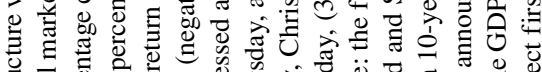

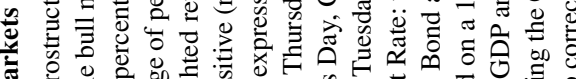

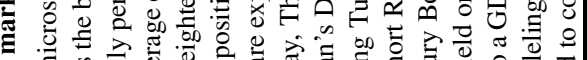

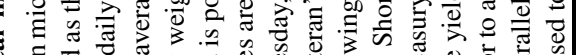

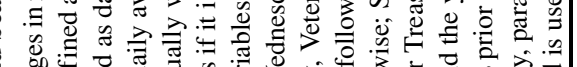

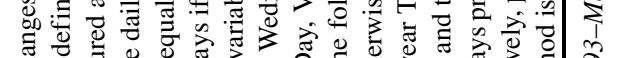

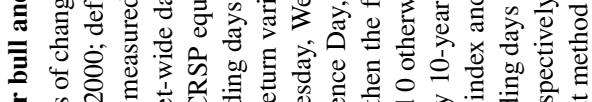

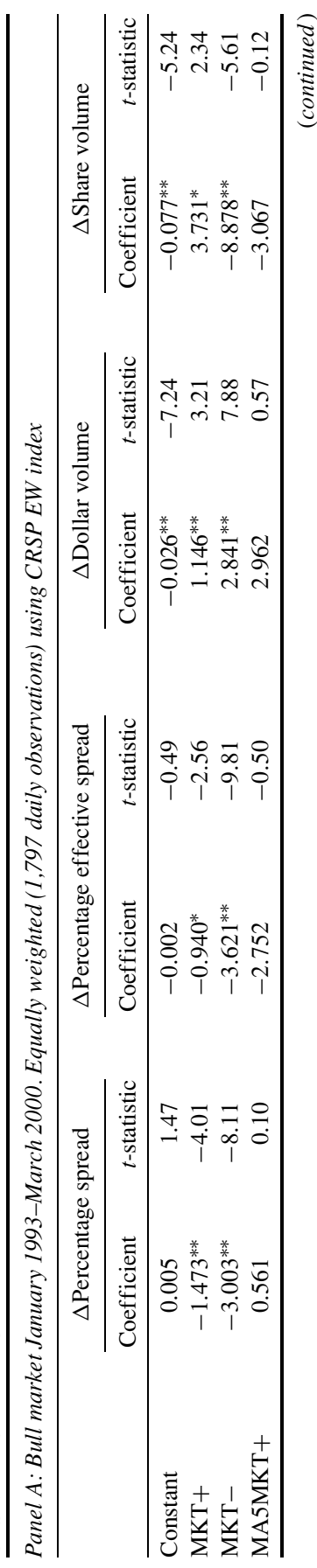

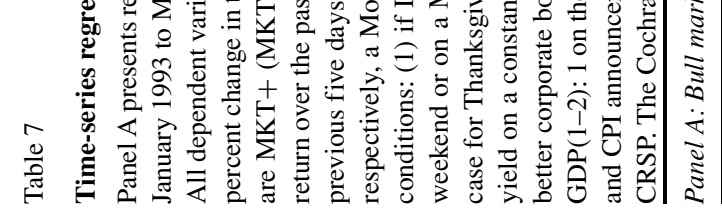

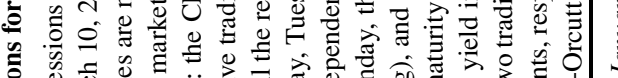

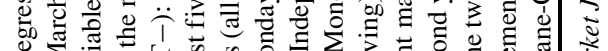

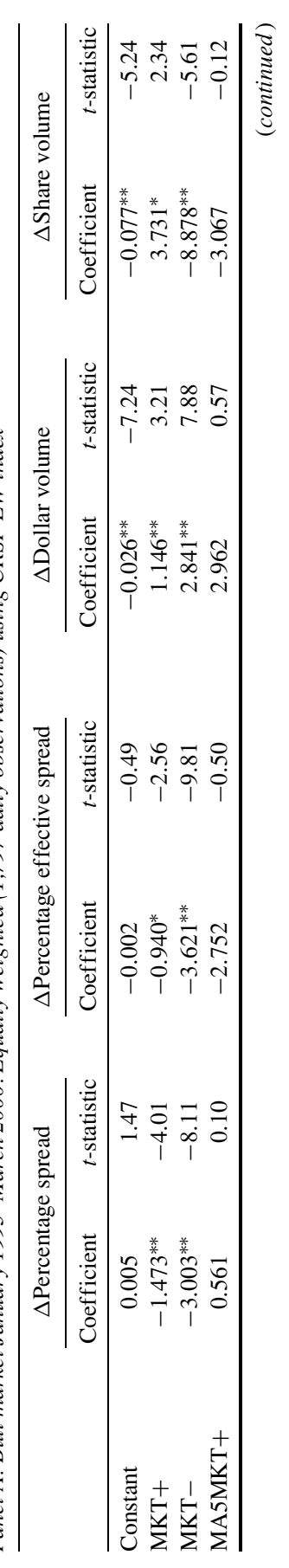




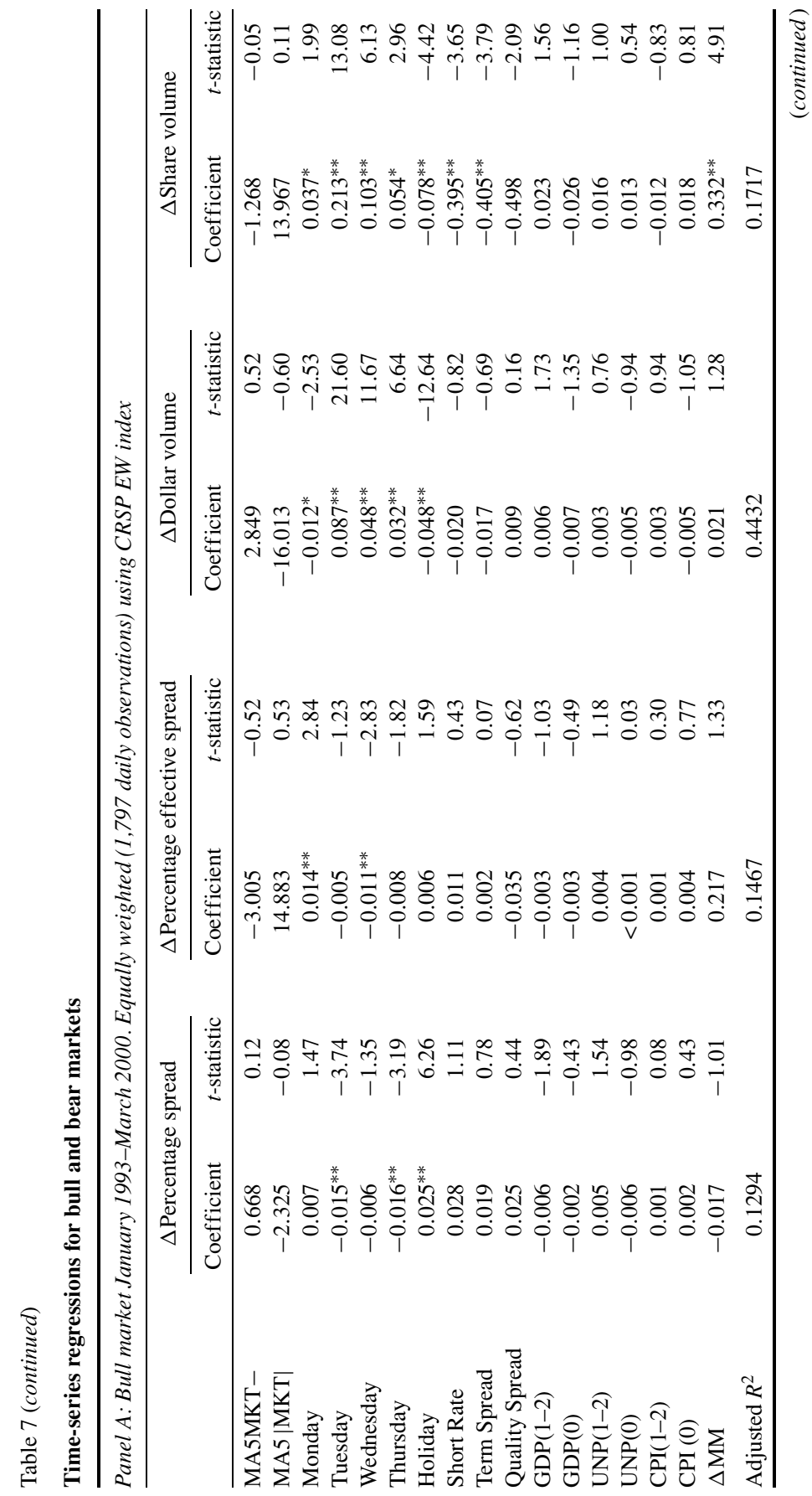




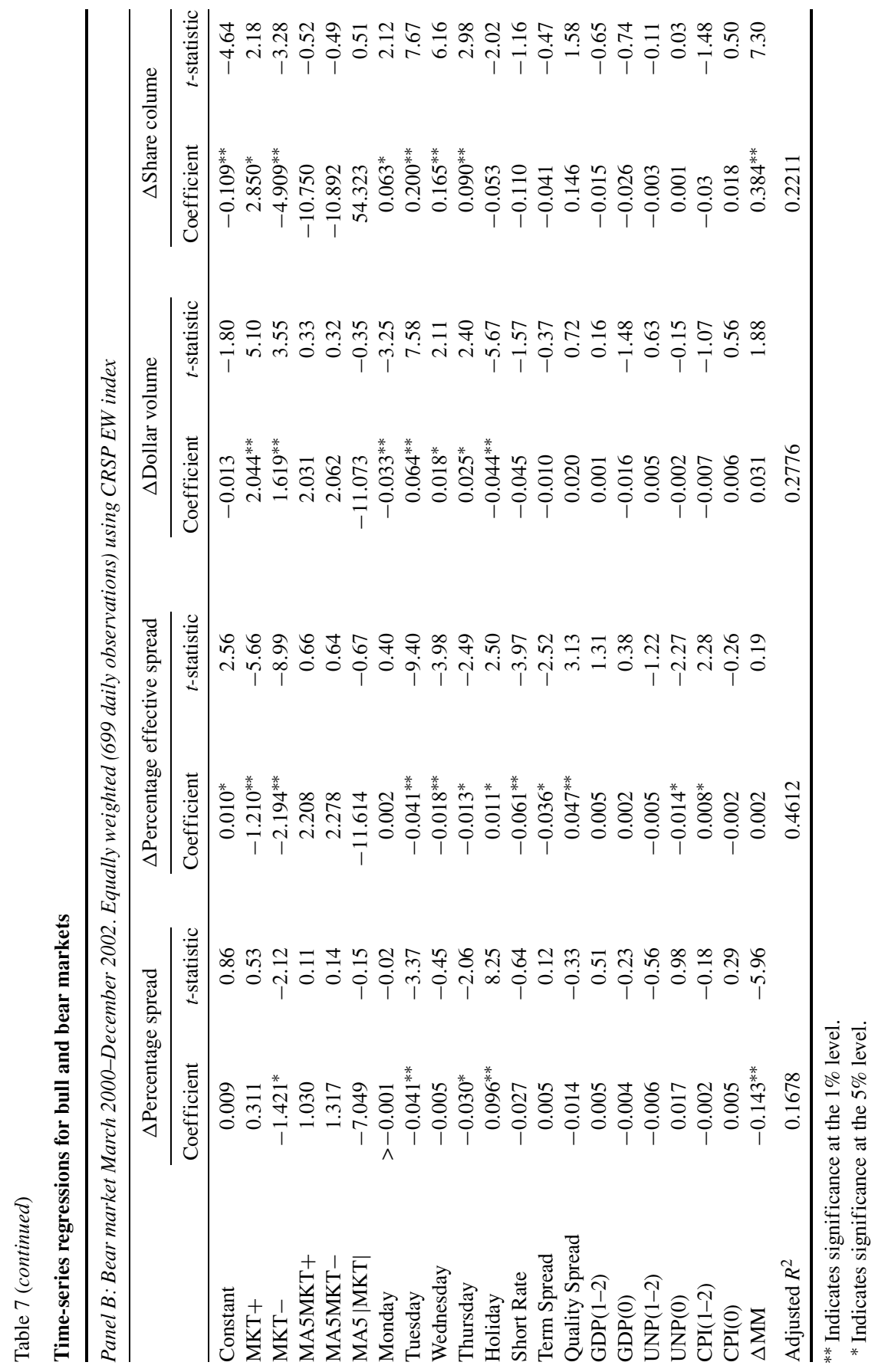


a result opposite of that found by Chordia, Roll, and Subrahmanyam (2001), which we find puzzling. In the bear market period, percentage effective spreads widen before a CPI announcement and narrow on an unemployment announcement. Both the results reflect market makers widening spreads before an important economic event and then narrowing them once the uncertainty is removed. The significance of such events in the bear market period but not the bull market may reflect an increased awareness of investors on the impact of macro events on the valuation of Nasdaq stocks. ${ }^{14}$ In essence, after the bubble burst, investors and market makers paid more attention to fundamentals.

\section{Conclusions}

We provide the first time-series examination of trading and trading costs over an extended period (1993-2002) on the Nasdaq stock market. Our study encompasses both a bull and bear market and several significant rule changes and tick reductions.

We find that spreads decline steadily over the period, and that spread reductions are not necessarily precipitated by rule changes or reductions in minimum tick-size changes. In fact, the results suggest that spreads are steadily declining on the Nasdaq market, and the tick-size reductions that occurred may be endogenous events necessitated by the continuing downward trend of spreads. There is evidence that wider spreads in the earlier years lead to significant autocorrelation in spread patterns, most likely due to price discreteness. This autocorrelation is diminished in later years when the tick size is smaller.

The composition of Nasdaq trades has changed significantly. Trade sizes have become smaller and trading frequency has increased. The changes do not appear to be caused directly by tick-size reductions and we speculate that they are more likely the result of greater retail participation in the market. Further evidence comes in the correlation between market performance and trading behavior. Volume appears to be directly related to the peak of the bull market, suggesting that the bull market drove trading behavior, particularly of retail investors.

Using the method of Chordia, Roll, and Subrahmanyam (2001), we examine some of the determinants of liquidity and trading activity for Nasdaq stocks during the full period and in the bull and bear markets. Market liquidity and trading activity are strongly related to concurrent market returns, but appear unrelated to previous market return volatility. There are persistent day-of-the-week effects that result in Fridays being characterized by higher spreads and lower volume, and Tuesdays having the lowest spreads and highest volume. Contrary to Chordia, Roll, and Subrahmanyam, we find that macroeconomic announcements have little impact on spreads for Nasdaq stocks. However, changes in key interest rate measures, such as the fed funds rate, the term spread, and quality spread, directly influence trading volume. When we

\footnotetext{
${ }^{14}$ Regulation Fair Disclosure (Reg FD) also occurred during our bear market period (effective October $23,2000)$, which also may have changed behavior. See Chiyachantana et al. (2004).
} 
look at the post-bull market period (from March 2000 onward), we find that some macroeconomic announcements and interest rate changes affect spreads. The results are consistent with Nasdaq investors becoming more aware of macroeconomic factors after the market collapse.

\section{References}

Atkins, A. and E. Dyl, 1997. Market structure and reported trading volume: Nasdaq versus the NYSE, Journal of Financial Research 20, 291-304.

Barclay, M., W. Christie, J. Harris, E. Kandel, and P. Schultz, 1999. Effects of market reform on the trading costs and depths of Nasdaq stocks, The Journal of Finance 54, 1-34.

Bessembinder, H., 1999. Trade execution costs on Nasdaq and the NYSE: A post-reform comparison, Journal of Financial and Quantitative Analysis 34, 387-408.

Bessembinder, H., 2003. Trade execution costs and market quality after decimalization, Journal of Financial and Quantitative Analysis 38, 747-777.

Chiyachantana, C., C. Jiang, N. Taechapiroontong, and R. Wood, 2004. The impact of fair disclosure on information asymmetry and trading: An intraday analysis, The Financial Review 39, 549-578.

Chordia, T., R. Roll, and A. Subrahmanyam, 2001. Market liquidity and trading activity, The Journal of Finance 56, 501-530.

Christie, W., J. Harris, and P. Schultz, 1994. Why did Nasdaq market makers stop avoiding odd-eighth quotes? Journal of Finance 49, 1841-1860.

Christie, W. and R. Huang, 1994. Market structures and liquidity: A transactions data study of exchange listings, Journal of Financial Intermediation 3, 300-326.

Christie, W. and P. Schultz, 1994. Why do Nasdaq market makers avoid odd-eighth quotes? Journal of Finance 49, 1813-1840.

Chung, K., C. Chuwonganant, and D. McCormick, 2004, Order preferencing and market quality on NASDAQ before and after decimalization, Journal of Financial Economics, 71, 581-612.

Goldstein, M. and K. Kavajecz, 2000. Eighths, sixteenths, and market depth: Changes in tick size and liquidity provision on the NYSE, Journal of Financial Economics 56, 125-149.

Heidle, H. and R. Huang, 2002. Information-based trading in dealer and auction markets: An analysis of exchange listings, Journal of Financial and Quantitative Analysis 37, 391-424.

Huang, R. and H. Stoll, 1996. Dealer versus auction markets: A paired comparison of execution costs on Nasdaq and the NYSE, Journal of Financial Economics 41, 313-357.

Schultz, P., 2000. Regulatory and legal pressures and the costs of Nasdaq trading, The Review of Financial Studies 13, 917-957.

Van Ness, B., R. Van Ness, and R. Warr, 2005. The impact of market maker concentration on Adverseselection costs for NASDAQ stocks, The Journal of Financial Research 28, 461-485. 